\title{
Proposta eletrosinestésica do grupo Duo Pantharei
}

Wilton Azevedo" Rita Varlesi"

\section{Resumo}

Este artigo visa apontar que foram os estudos dos instrumentos de percussão introduzidos em orquestra os responsáveis pelo avanço do caminho para a música de vanguarda. A música eletroacústica visava também aos dados de frequência percussiva em sua variedade de timbres, mais tarde explorada por Henri Chopin e a poesia sonora. A aplicação de Instrumentos de percussão, hoje, em poesias sonoras e performances que envolvem variações de frequência acústica, introduzida por modelos matemáticos em sistemas digitais, promove sem nenhuma dificuldade, um diálogo sonoro poético pertinente e eficaz na elaboração desta linguagem.

Palavras-chave: Eletrosinestésico. Frequência acústica. Eletroacústica.
Em 1912, o pesquisador e físico alemão, Winfried Otto Schumann, depois de anos debruçado sobre o funcionamento das frequências das ondas magnéticas, descobriu o que ficou conhecido como ressonância de Schumann. Em suma, a ideia consistia em relatar as ondas de som de frequências muito baixas existentes na camada da ionosfera da terra na intenção de identificar como as correntes eletromagnéticas entram e saem do nosso planeta.

Você pode estar se perguntando: o que isso tem a ver com oralidade, poesia sonora ou melhor, com a nossa própria voz? Schumann descobriu a frequência de nosso planeta do ponto de vista so-

\footnotetext{
Professor Pesquisador do programa EAHC - Educação, Arte e História da Cultura da Universidade Presbiteriana Mackenzie e coordenador do Laboratório de pesquisa LHUDI - Laboratório de Humanidades Digitais.

** Doutoranda pela Universidade Presbiteriana Mackenzie no Programa EAHC - Educação, Arte e História da Cultura - linha de pesquisa: Linguagens e Tecnologia. Mestre em Comunicação e Semiótica pela PUC - Pontifícia Universidade Católica de SP.
}

Data de submissão: mar. 2015 - Data de aceite: maio 2015 http://dx.doi.org/10.5335/rdes.v11i1.4977 
noro, ou seja, se nosso planeta tivesse um coração, o pesquisador sabia em que frequência de ressonância esse coração bateria: 7,83 hertz.

$\mathrm{O}$ físico alemão chegou a afirmar que a estabilidade da saúde humana está diretamente ligada a essa frequência. Verdade científica ou não, o que a vanguarda sonora do século passado mais fez foram experimentos sonoros, tentando detectar até que ponto o ouvido humano estabelece relações melódicas e harmônicas e o quanto a ciência se relaciona com a produção poética do século XX.

Ao se referir ao domínio eletroacústico, Pierre Boulez afirma que "a notação representa no mínimo fator para que ao menos uma sociedade, por mais restrita que seja, possa falar a mesma língua” (apud MENEZES, 1999, p. 53).

A manifestação do que chamamos de cultura oral ou "oralidade nômade" segue o caminho, e sempre seguiu, do ritualístico, da repetição, e, muitas vezes, do excesso, para poder ressaltar a "mesma língua". Repetição e excesso é a grande marca que a investigação artística do século XX, na natureza da produção artística em todos os campos de seus códices, foi incisiva em provar: a repetição pode gerar a reinvenção do já conhecido. O minimalismo de Steve Reich (1936) e de Alvin Lucier (1931) é um dos grandes exemplos disso.

A intenção deste texto não será fazer uma explanação sobre a história da música eletroacústica, muito menos uma demonstração teórica de compositores que o realizaram de maneira brilhante.
O objetivo aqui é apontar que a vanguarda da música e as pesquisas sonoras do século passado também privilegiaram as repetições em excesso - loopings - como um processo ritualístico existente nas frequências sonoras e, muitas vezes, com a distorção da fala.

Ao introduzirmos elementos sonoros que possam soar como processos melódicos ou harmônicos para nossos ouvidos, é possível observar as semelhanças e os paralelos entre o que se fazia no Brasil do século XVIII - com a chegada dos escravos africanos em nossas terras, dando início à prática desses rituais - e na Europa dos anos 1930, após a invenção de Leon Theremin em 1919, quando as modificações das frequências do som de davam por afastamento ou aproximação de uma antena. Esses dois continentes, em épocas totalmente distantes, acabaram por oferecer para o século XX a eloquência rítmica da fala e os sons modulados da frequência eletrônica.

Figura 1 - Leon Theremin em 1919 com seu
protótipo

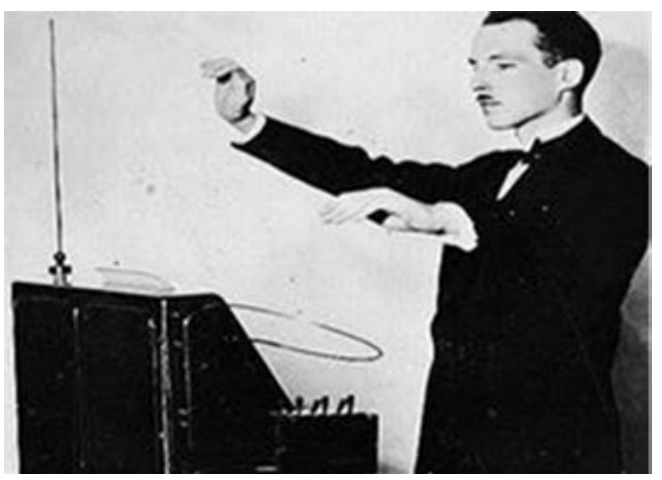

Fonte: Disponível em: http://inda.nmelindo.com/2014/06/ theremin-invencao-e-usos 


\section{Frequência analógica e digital}

Em 2009, quando eu estava em Paris, fiz um trabalho em formato de vídeo poesia intitulado Secret ${ }^{1}$. Trata-se de um poema que eu havia escrito em inglês, e para o qual, com a ajuda do poeta americano Steve Dalachinski, que deu voz ao texto, criei uma sonoridade intimista e, ao mesmo tempo instigamos a pergunta feita a nós mesmos: What can keep a secret?

Para que esse efeito fosse sensivelmente assimilado, trabalhei em uma trilha musical, quase em um toque serialista com cello e piano, que, acompanhando a voz de Dalachinski, dava ao andamento sonoro sua prosódia apropriada.

Figura 2 - Secret (2009) - Wilton Azevedo, voz Steve Dalachinski, Paris

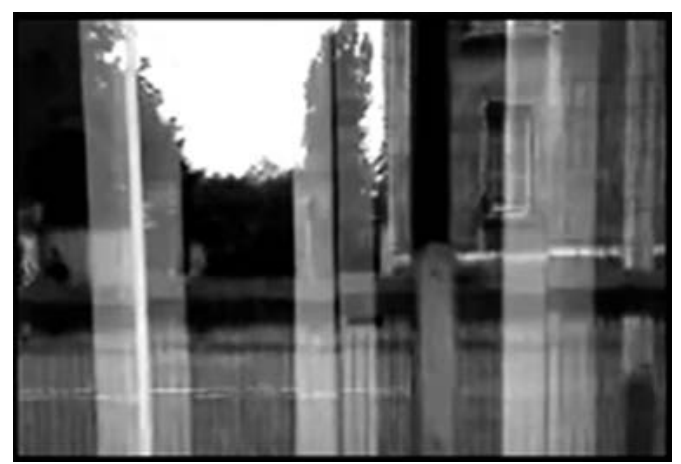

Foto: Wilton Azevedo.
SECRET - Wilton Azevedo

What can keep a secret? The time?

No.

This is too fast

To remain secret. People?

No.

They die. Life?

Not too.

These changes as well as love.

The one secret that can save,

In the silence.

As the air of Paris Locked in a box As a souvenir

A sound that never discover And by insisting that the exception

Of the senses.

A secret

Only Secret

Is the complicity in this silence.

So,

As if listening to the wind say The lines with the cardinal. A secret must be kept,

Stored Given

To know

If it is true

Or rather

If you really happened.

Yes, because not everything which we live, Happens.

Nothing is a lie in a secret And much less true. The only error

You want to be with someone Believe that

No secret 
We want to be with the other Even if the vital signs of a love Not survive more

Involved in human cognition.

The years are going to clean...

What was secret

Was

Locked

In the story I made up

To know

What I have never ever loved.

Figura 3 - Secret (2009) - Wilton Azevedo,voz Steve Dalachinski, Paris

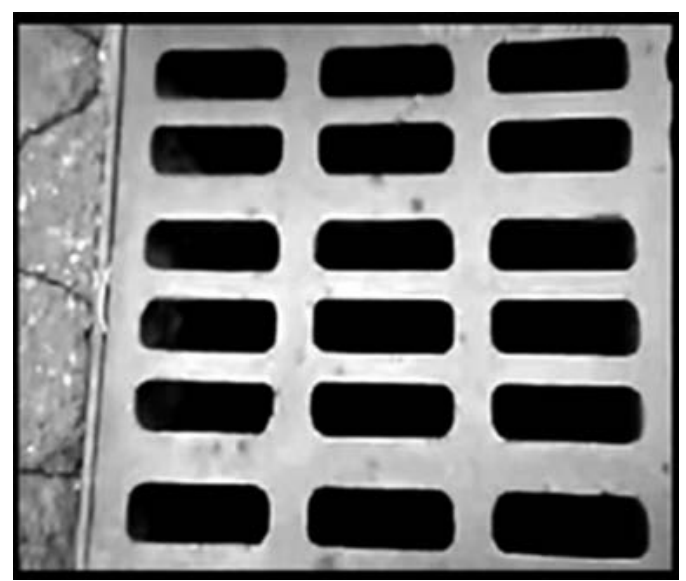

Foto: Wilton Azevedo.

O trabalho Secret (2009) me possibilitou perceber que eu poderia tornar esse aspecto da prosódia algo mais polifônico e com uma parataxe sonora mais intensificada, com sobreposição de vozes dos instrumentos, das falas. A sincronização do compasso sonoro poderia ser mixada com sons de vozes, seu timbre e tons alterados.

A música com um sentido serialista, pausa, a fala de Dalachiski, criando uma terceira frequência que pode ser vista como parte da narrativa que, por sua vez, devolve ao texto o andamento de sua prosódia.

$\mathrm{O}$ andar dado pelo corte das cenas, somando-se à oralidade e à trilha musical, fazem de Secret um trabalho que consideramos "limpo" na concepção da palavra, em que três códigos conversam e devolvem ao leitor que até um segredo tem uma rota, um caminho e uma sonoridade móvel.

\section{Pantharei o Som Sinestésico}

Figura 4 - Logotipo do Grupo Duo Pantharei, 2013

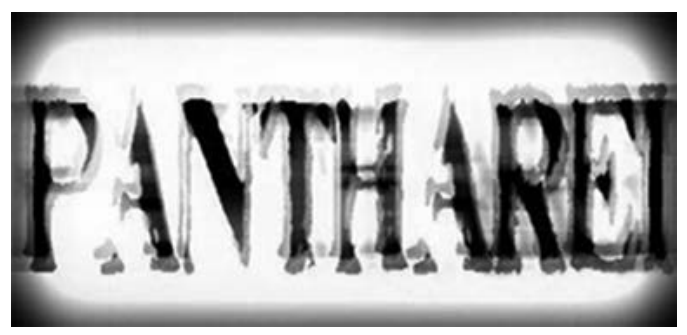

Fonte: Logotipo Wilton Azevedo.

O trabalho sonoro PANTHAREI ${ }^{2}$ pode ser considerado um "experimento". Sua elaboração, executada no Laboratório de Pesquisa Interdisciplinar da Universidade Presbiteriana Mackenzie em São Paulo e na PUC-SP, possibilitou escutar e concluir, com muito cuidado e rigor, que o conceito de eletroacústica e sinestesia na execução dos seus timbres vão ao encontro, na busca pelo excesso e pela repetição, das experiências praticadas pelo grande poeta sonoro Henri 
Chopin (1922-2008). Entretanto, o que era voz, oralidade, se mistura com os timbres de baixa frequência obtidos pela programação e a alta frequência produzida pela distorção eletrônica da guitarra.

Figura 5 - Extreme Sub- Voicive. Pantharei 2013

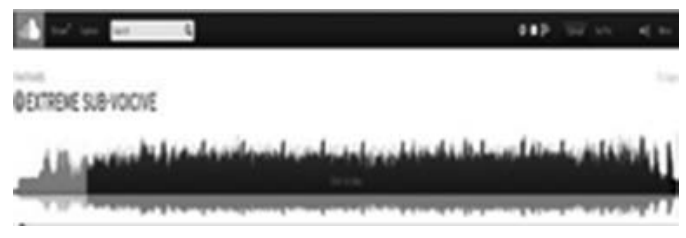

Fonte: http://wiltonazevedo.tumblr.com/page/3.

O algoritmo como escritura e mesmo a simulação sonora, do ponto de vista teórico, não trouxe tanta novidade, em termos do estudo dos sons; isto porque 0 som tem uma vantagem: sua constituição sígnica é virtual justificado pela essência de seu código. Não há, pelo menos no meu conhecimento, uma materialidade do som, exceto seus efeitos na recepção e na materialidade da fita magnética usada por Pierre Schaeffer ${ }^{3}$ na música Concreta, produzindo sons em looping.

$\mathrm{O}$ fato de um som simulado de um tímpano se parecer com um tímpano de orquestra pode trazer perplexidade para o público por aparentar tal semelhança, mas, para um músico, nada disso afeta, pois ele identificará as grandes mudanças de timbre entre os tímpanos em questão. Isso significa que as descobertas dos sons e as pesquisas artísticas feitas no século passado já haviam comprovado o fato de que ruído e o excesso contribuíram e contribuem para o experimento sonoro.
Figura 6 - Retoric Subject. Pantharei, 2013

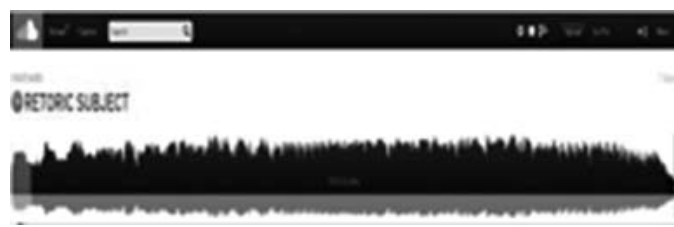

Fonte: http://wiltonazevedo.tumblr.com/page/3.

O objeto sonoro do cotidiano, como os ruídos de uma cidade, e suas falas - muitos deles já fazem parte de certo ritual do dia a dia -, está na mesmice que foi o passar dos anos, ou melhor, das décadas no século $\mathrm{XX}$, de tal maneira que pudemos observar que o ritualístico não pertence apenas às manifestações folclóricas ou étnicas, mas também trata-se de uma retomada de uma nova cultura poética. Esse foi o caso da contracultura literária americana, quando autores como William S. Boughrous entraram em contato com grupos indígenas do sul da Califórnia para procurar novos métodos de criação, incluindo alucinógenos usados em rituais e seus gritos tribais. Outro exemplo é o de John Lennon na canção Mother 1970 album John Lennon/Plastic Ono Band, que se utiliza desse ritual ao gritar a frase, Mother, you had me/But I never had you, em suas estrofes famosas para o processo dessa descoberta oral. 
Figura 7 - Apresentação Duo Pantharei no evento SMETRACK! Anos - Luz de Walter Smetak

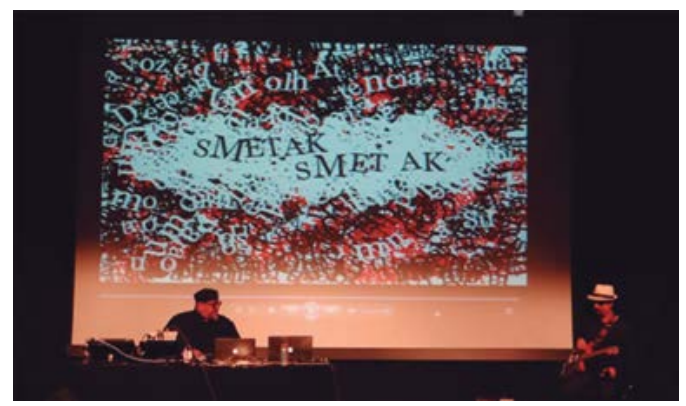

Foto: Rita Varlesi.

Nessa descoberta, voz e percussão ganham novos espaços também, já que sempre foram vistos, até o século XIX, como instrumentos ditos "não nobres". Sua inclusão em orquestras era rara. Muitas vezes não eram aceitos já que carregavam como marca cultural algo que os ligava a manifestações tribais, e, assim, eram considerados menos importantes para uma sociedade aristocrática.

$\mathrm{O}$ interessante dessa história é que, no século XX, o instrumento de percussão será o grande protagonista desta vanguarda: Parade, de Erik Satie (18661925), Piano Preparado, de John Cage (1912-1992), os órgãos com maracás de Steve Reich, os poemas eletrônicos (sonoros) percussivos de Edgar Varèse (1883$1965)^{4}$, as fontes de ondas senoidais de Karlheinz Stockhausen (1928-2007) e os ruídos de uma torcida de futebol de Gilberto Mendes $(1922)^{5}$, para citar alguns.

Tal vanguarda, sem dúvida, foi possível graças à atenção dada aos instrumentos de percussão no momento em que respostas para algumas questões mais práticas poderiam ser percebidas na grande variedade de timbres executados. Hoje, quando ouvimos poesias sonoras e performances percussivas e introduzimos sons eletroacústicos programados em um computador, podemos perceber, sem nenhuma dificuldade, o quanto esse diálogo sonoro é pertinente e eficaz.

Figura 8 - Apresentação Duo Pantharei no evento SMETRACK! Anos - Luz de Walter Smetak

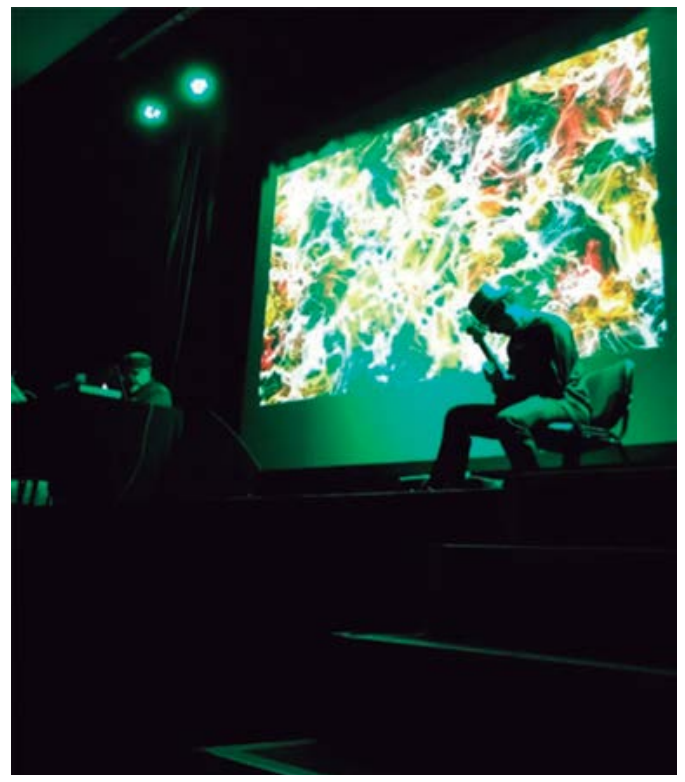

Foto: Rita Varlesi

O som, na repetição excessiva e os loops eletroacústicos programados nos fazem comprovar que os ruídos do cotidiano e os retornos em forma de eco da frequência sonora quase que ritualístico, tem como seu referente o meio ao qual pertencem. Podemos detectar esse dado de maneira simples, ou podemos investir 
em pesquisa tecnológica, quando nossos sentidos se fazem limitados para tal averiguação.

O espaço para a audição, os concertos, acabam por ser modificados. Podemos, nas ruas de hoje, ter sensações sonoras nem sempre possíveis de serem percebidas com tal requinte em um ambiente construído para isso. A produção digital sonora fez aguçar nossa audição para um novo formato sobre sons, seja de natureza caógena ${ }^{6}$ ou não, mesmo com essa evolução tecnológica.

Figura 9 - Wilton Azevedo - Duo Pantharei no evento SMETRACK! Anos - Luz de Walter Smetak

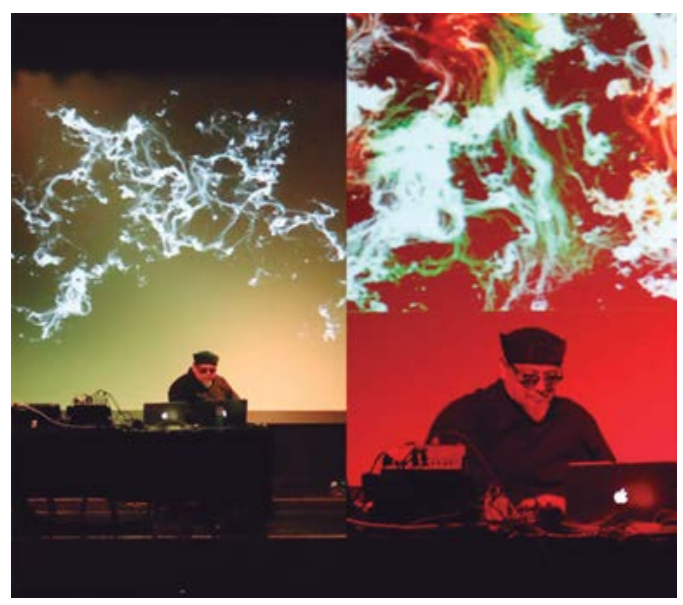

Foto: Rita Varlesi

Sendo pesquisadores, não podemos, de maneira alguma, esvaziar a discussão e o conceito sobre o sentido da produção poética nesses novos dispositivos. Não estou, com isso, afirmando que existe uma produção poética nos meios digitais, nem que somos obrigados a te-la, mas sim, de sermos mais honestos com a produção artística de qualquer natureza.

\section{Group Duo Pantharei's proposal electrosynestesia}

\section{Abstract}

This article aims to points that studies of percussion instruments that was introduced in classical orchestra that gave the advance to the avand guard music. Electroacoustic music aimed for the percussive frequency data in its variety of timbres later exploited by Henri Chopin and sound poetry. Percussion instruments Today, when we hear sound poetry and performances involving sound frequency variations introduced by mathematical models in digital systems, we can see without any difficulty, how much this sound poetic dialogue is relevant and effective with digital devices.

Keywords: Eletrosinestésico. Acoustic frequency. Electroacoustic.

\section{Notas}

1 http://www.youtube.com/watch?v=q_m5p-2R5Ko.

2 PANTHAREI é um grupo de estudos de sonoridades sinestésicas criada pelo Prof. Dr. Wilton Azevedo -UPM e Sergio Basbaum PUC-SP: https://soundcloud.com/pantharei.

3 Pierre Schaeffer: "Étude violette" (1948),from "Cinq études de bruits".

4 Ionisation (1929/1931) para treze percussionistas.

5 Santos Football Music (1969).

6 O termo caogino vem da teoria da informação de Norbert Wiener para apresentar que um sistema redundante era afetado por um ruído. 


\section{Referências}

BARRIÈRE, Françoise; BENNETT, Gerald. Composition/diffusion en musique électroacoustique. v. 3 de Actes (Académie Bourges), Académie Bourges: Editora Mnémosyne, 1998. v. 3 Academie Internationale de Musique Electroacoustique, v. 3, 1997.

BERGSON, Henri. Matière et mémoire, essai sur la relation, Une édition électronique réalisée à partir du livre de Henri Bergson (1859-1941), 1939.

BERGSON, Henri. Matière et mémoire. Essai sur la relation du corps à l'esprit. (1939). Paris: Les Presses universitaires de France, 1965, 72e édition, 282 pp. Collection: Bibliothèque de philosophie contemporaine. Disponível em: http://bibliotheque.uqac. uquebec.ca/index.htm>. Acesso em: 20 maio 2015.

BOBILLOT, Jean-Pierre. Bernard Heidsieck: poésie action. Editora J. M. Place, DU CORPS À L'ESPRIT, Édition complétée jeudi le 18 juillet 2003 à Chicoutimi, Québec, 1996.

CABREIRA, Daniel Héctor, Lo tecnológico y lo imaginário lãs nuevas tecnologias como creencias y esperanzas colectivas. Buenos Aires: Biblos, 2006.

DELEUZE, Gille. Diferença e Repetição. Tradução Luiz Orlandi Roberto Machado, Vértice: revista de cultura e arte, Edições 123-125, Universidade de Michigan 2005.

DELEUZE, Gille. Du corps à l'Esprit. Édition complétée jeudi le 18 juillet 2003 à Chicoutimi, Québec.

MENEZES, Flo. Atualidade estética da música eletroacústica. São Paulo: Unesp, 1999. 